\title{
DIFERENTES ÉPOCAS DE COLHEITA E QUALIDADE FISIOLÓGICA DE SEMENTES DE CEVADA ${ }^{1}$
}

\author{
LILIAN MADRUGA DE TUNES ${ }^{2}$, ANTONIO CARLOS SOUZA ALBUQUERQUE BARROS 3 , \\ PABLO GERZSON BADINELLI ${ }^{4}$, DANTON CAMACHO GARCIA ${ }^{5}$
}

\begin{abstract}
RESUMO - O trabalho foi realizado com o objetivo de avaliar o efeito de diferentes épocas de colheita sobre a qualidade fisiológica de sementes de cevada. Foram utilizadas sementes das cultivares MN 721 e Scarlett. A colheita de sementes foi realizada com 118, 129 e 140 dias após a semeadura. O grau de umidade, na ocasião das amostragens, foi de $25 \%, 18 \%$ e $13 \%$, respectivamente, na primeira, segunda e terceira colheita, para a cultivar MN 721 e, para a cultivar Scarlett, foi de $26 \%, 19 \%$ e $13 \%$, respectivamente nas três colheitas. As sementes foram secas em estufa com circulação de ar forçado até atingir grau de umidade de $13 \%$ e, então, armazenadas em câmara fria e seca $\left(17{ }^{\circ} \mathrm{C}\right.$ e UR $\left.45-50 \%\right)$. Antes da realização das análises, parte das sementes foi submetida ao pré-esfriamento de 5 a $10{ }^{\circ} \mathrm{C}$ por sete dias para a superação da dormência. As sementes foram avaliadas pelos testes de germinação, primeira contagem da germinação, comprimento de plântulas (parte aérea e raiz), fitomassa seca (parte aérea e raiz), teste de tetrazólio e envelhecimento acelerado para cada cultivar nas diferentes épocas de colheita, logo após a superação da dormência. As cultivares de cevada após a colheita apresentam alta intensidade de dormência. De acordo com a cultivar, a dormência manifesta-se mais acentuada quando as sementes são colhidas com grau de umidade em torno de $13 \%$. As sementes de cevada com melhor qualidade fisiológica são as obtidas com graus de umidade de $26 \%$ (118 dias após a semeadura) e 18\% (129 dias após a semeadura) para as cultivares Scarlett e MN 721, respectivamente.
\end{abstract}

Termos para indexação: Hordeum vulgare L., grau de umidade, vigor, germinação.

\section{THE EFFECTS OF HARVEST PERIODS ON THE SEED QUALITY OF BARLEY}

\begin{abstract}
The objective of this study was to evaluate the effect of different harvesting periods on the physiological quality of barley seeds. Seeds of cultivars MN 721 and Scarlett were used. The seeds were harvested at 118, 129 and 140 days after sowing. The humidity at the time of sampling was $25 \%, 18 \%$ and $13 \%$ in the first, second and third harvests respectively for the cultivar MN 721, and for the cultivar Scarlett it was $26 \%, 19 \%$ and $13 \%$, respectively for the same periods. The seeds were oven-dried by forced air circulation down to $13 \%$ moisture content and then stored in a cold room ( $17^{\circ} \mathrm{C}$ and RH $45-50 \%$ ). Before analysis, the seed was subjected to pre-cooling of 5 to $10{ }^{\circ} \mathrm{C}$ for seven days to break dormancy. The seeds were evaluated by
\end{abstract}

${ }^{1}$ Submetido em 07/08/2009. Aceito para publicação em 26/01/2010. Parte da Dissertação de Mestrado em Ciências da UFPel, pelo primeiro autor.

${ }^{2}$ Engenheira Agrônoma. Mestre do Programa de Pós-graduação em Ciência e Tecnologia de Sementes, Dep. Fitotecnia-FAEM-UFPel. lilianmtunes@, yahoo.com.br.

${ }^{3}$ Engenheiro Agrônomo, Dr., Professor Associado, Departamento de Fitotecnia, Bolsista de Produtividade em Pesquisa - CNPQ, FAEM-UFPel, Caixa Postal:
354, CEP 96001-970, Pelotas, RS, Brasil. acbarros@ufpel.edu.br.

${ }^{4}$ Engenheiro Agrônomo. Mestre do Programa de Pós-graduação em Fisiologia Vegetal, Dep. Botânica - Biologia - UFPel. pgbagro@yahoo. com.br.

${ }^{5}$ Engenheiro Agrônomo, Dr., Professor Departamento de Fitotecnia, Centro de Ciências Rurais (CCR), Universidade Federal de Santa Maria (UFSM), 97105-900, Santa Maria, RS, Brasil. dantongarcia@smail.ufsm.br. 
the standard germination tests, first count of germination, seedling length (shoot and root), dry weight (shoot and root), tetrazolium and accelerated ageing for each cultivar at the different harvest times after breaking dormancy. After harvesting, barley cultivars show a high level of dormancy. Depending on the cultivar, dormancy is most pronounced when seeds are harvested with a humidity content around $13 \%$. The barley seeds with better physiological quality were obtained with moisture contents of 26\% (118 days after sowing) and 18\% (129 days after sowing) for the Scarlett and MN 721 cultivars, respectively.

Index terms: Hordeum vulgare L.; moisture; vigor; germination.

\section{INTRODUÇÃO}

A cevada (Hordeum vulgare L.) é o quarto cereal em superfície cultivada no mundo, depois do trigo, arroz e milho. Em função do melhoramento genético e do desenvolvimento de técnicas de manejo, cada vez mais apropriadas, a cultura foi difundida pelo sul do Brasil, estendendo-se aos três estados, onde se localizam as melhores áreas, em termos de clima e solo, para o cultivo desse cereal (Yalçin et al., 2007).

Geralmente, os parâmetros utilizados para indicar a época de colheita de sementes de cevada são o grau de umidade e o aspecto das plantas. Entretanto, esses parâmetros podem sofrer modificações devido a fatores climáticos, temporais e genéticos, não constituindo indicativos seguros do ponto de colheita, visando à obtenção de sementes de qualidade. A cevada caracteriza-se por ser altamente sensível a precipitações no momento da colheita, principalmente, pelo prejuízo promovido à germinação das sementes (Reuss et al., 2003).

As sementes de cevada chegam à maturidade fisiológica com grau de umidade em torno de $30 \%$. Seria importante realizar a colheita nesse ponto ou o mais próximo possível, pois a semente encontra-se com máximo potencial fisiológico (Marcos Filho, 2005). Porém, nessa fase, o grau de umidade das sementes é elevado, e as plantas ainda se encontram com grande número de folhas verdes, o que torna praticamente inviável a colheita mecânica (Zimmer, 2006).

$\mathrm{O}$ intervalo entre a maturidade fisiológica e a colheita é crítico, pois as sementes permanecem ligadas à planta apenas fisicamente, ficando expostas a uma série de condições adversas no campo (Dias, 2001). As sementes de cevada apresentam certo grau de dormência e assim, evitam a germinação na espiga, principalmente, em climas com possibilidade de períodos úmidos e chuvas prolongadas na época de colheita, como ocorre no Sul do Brasil (Barros e Peske, 2006).

A qualidade fisiológica é a capacidade potencial das sementes de produzirem, sob condições favoráveis, plantas vigorosas (Vieira e Rava, 2000). Pádua e Vieira (2001), ao avaliarem a germinação e o vigor de sementes de milho colhidas em diferentes épocas, concluíram que as sementes colhidas tardiamente, reduzem suas propriedades fisiológicas com maior rapidez que as provenientes de colheita precoce. Barros e Peske (2006) relataram que a instabilidade no rendimento ou qualidade decorre, principalmente, da vulnerabilidade da cultura a fatores adversos de clima (geadas, altas temperaturas, seca, excesso de água) e solo (acidez, deficiências e toxidez mineral).

Sementes de alta qualidade envolvem uma série de características, dentre as quais estão os atributos fisiológicos (germinação e vigor) e sanidade (Marcos Filho, 2005). A qualidade das sementes representa a capacidade de originar uma lavoura uniforme, constituída de plantas vigorosas e representativas da cultivar, livre de plantas invasoras ou indesejáveis (Popinigis, 1985).

O objetivo do trabalho foi avaliar a influência de diferentes épocas de colheita sobre a qualidade fisiológica de sementes de duas cultivares de cevada.

\section{MATERIAL E MÉTODOS}

O estudo foi conduzido na empresa Westermann, localizada no Município de Piratini/RS e as avaliações foram realizadas no Laboratório Didático de Análise de Sementes, do Departamento de Fitotecnia, da Faculdade de Agronomia Eliseu Maciel, Universidade Federal de Pelotas, situado a $31^{\circ} 45^{\prime} 45^{\prime \prime}$ de latitude sul, $52^{\circ} 19^{\prime} 55$ de longitude oeste de Greenwich. Foram utilizadas sementes de duas cultivares de cevada, MN 721 e Scarlett, safra 2007.

A cultivar MN 721 é originada da AMBEV (Companhia-AmBev Americana da Bebida), apresenta ampla adaptação e responde a ambientes de baixa fertilidade. A cultivar Scarlett é de origem Argentina, apresenta rendimento elevado, superando as cultivares mais produtivas e se adapta tanto a clima frio, quanto ao quente. A área experimental foi de aproximadamente 0,5 ha para cada cultivar.

A colheita foi realizada quando as sementes atingiram 
grau de umidade inferior a $30 \%$ e as plantas estavam com 118,129 e 140 dias após a semeadura. O grau de umidade, na ocasião das amostragens, foi de $25 \%, 18 \%$ e $13 \%$ respectivamente na primeira, segunda e terceira colheita, para a cultivar MN 721 e, para a cultivar Scarlett, foi de $26 \%, 19 \%$ e $13 \%$, respectivamente nas três coletas. Após a colheita, apresentaram em média, 10 a 12\% de proteína, dentro dos padrões de qualidade estabelecidos na Portaria $\mathrm{n}^{\circ}$ 691 de 1996 (Brasil, 1996).

As sementes foram secas em estufa com circulação forçada de ar, até atingir grau de umidade de $13 \%$ e, então, armazenadas em câmara fria e seca, à temperatura de $17^{\circ} \mathrm{C}$ e umidade relativa de 45 a $50 \%$, por 18 dias. Antes da realização das análises, parte das sementes foram submetidas ao préesfriamento de 5 a $10{ }^{\circ} \mathrm{C}$, por sete dias para a superação de dormência, conforme as Regras para Análise de Sementes (Brasil, 1992).

Foram realizados os testes de germinação, primeira contagem de germinação, comprimento de plântulas (parte aérea e raiz), fitomassa seca (parte aérea e raiz), teste de tetrazólio e envelhecimento acelerado para cada cultivar nas diferentes épocas de colheita, logo após a superação da dormência.

$\mathrm{O}$ teste de germinação foi realizado com quatro subamostras de 100 sementes, semeadas em papel toalha umedecido com água destilada na proporção de 2,5 vezes a massa do papel seco. O teste foi conduzido em temperatura constante de $20{ }^{\circ} \mathrm{C}$, sendo as contagens realizadas no quarto e sétimo dia após a semeadura e, juntamente com o teste, foi realizada a primeira contagem, determinando-se a porcentagem de plântulas normais no quarto dia após a instalação e os resultados foram expressos em porcentagem de plântulas normais (Brasil, 1992).

Avaliou-se o comprimento médio de 10 plântulas normais, escolhidas aleatoriamente, obtidas a partir da semeadura de quatro subamostras de 30 sementes por cultivar e época de colheita, no terço superior da folha de papel toalha, seguindo a metodologia descrita por Nakagawa (1999). Os rolos de papel contendo as sementes permaneceram por sete dias em germinador a $20{ }^{\circ} \mathrm{C}$. Em seguida, avaliou-se o comprimento da parte aérea e da raiz das plântulas, com auxílio de régua milimetrada. O comprimento médio da parte aérea e da raiz foi obtido, somando-se as medidas de cada repetição e dividindo-se pelo número de plântulas normais sendo os resultados expressos em centímetros.

Após a mensuração, as plântulas foram seccionadas, separando-se a parte aérea do sistema radicular e imediatamente pesada. Em seguida, o material foi colocado em cápsulas de alumínio, mantido em estufa com convecção regulada a $65{ }^{\circ} \mathrm{C}$ durante $96 \mathrm{~h}$. Posteriormente, foi avaliada a fitomassa seca, utilizando-se balança de precisão $(0,0001 \mathrm{mg}) \mathrm{e}$ os resultados expressos em g.plântula-1 (Nakagawa, 1994).

Para o teste de tetrazólio, foram utilizadas 25 sementes por subamostra, as quais foram submetidas à embebição em água destilada, por $20 \mathrm{~h}$ a $25^{\circ} \mathrm{C} \pm 1{ }^{\circ} \mathrm{C}$, em germinador. Ao término da embebição, as sementes foram seccionadas no sentido longitudinal, com exposição do embrião e endosperma. Logo em seguida, foram imersas em solução de sal de tetrazólio $(2,3$, 5 - trifenil cloreto de tetrazólio) $\mathrm{com} \mathrm{pH} 7,0$, na concentração de $0,1 \%$, durante $30 \mathrm{~min}$ (Fiala, 1984).

$\mathrm{O}$ teste de envelhecimento acelerado foi realizado em caixas de plástico tipo "gerbox", onde $30 \mathrm{~g}$ de sementes foram distribuídas uniformemente sobre tela e abaixo dessa, colocada uma lâmina de água destilada. Em seguida, as sementes foram submetidas à temperatura constante de $41{ }^{\circ} \mathrm{C}$, por 72 horas (Marcos Filho, 1994). Ao término desse período, as sementes foram submetidas ao teste de germinação, conforme descrito anteriormente.

Para cada cultivar foi conduzido um experimento com delineamento inteiramente casualizado com quatro repetições, onde os tratamentos foram constituídos pelas três épocas de colheita. Após a análise de variância, foi realizada análise de regressão, utilizando o método dos polinômios ortogonais (Storck et al., 2006).

\section{RESULTADOS E DISCUSSÃO}

Foi verificado que as duas cultivares apresentaram alto grau de dormência (Figura 1), em todas as épocas de colheita, indicando a necessidade de tratamento específico para a utilização dessas sementes, logo após colhidas. Nas três épocas de colheita, as amostras de sementes apresentaram germinação abaixo de $65 \%$, o que torna evidente o prejuízo proporcionado pela antecipação da colheita sobre a qualidade fisiológica, em razão das diferenças de maturidade das espigas (Sterling et al., 2003).

Foi observado que o pré-esfriamento (Figura 2) é um método adequado para a superação de dormência, visto que nas épocas analisadas para a colheita (MN 721 aos 118 dias e Scarlett aos 129 dias após semeadura), a germinação foi acima de $92 \%$, sendo elevada para os padrões de sementes, onde o mínimo exigido é de $80 \%$, que é o padrão mínimo de comercialização (Brasil, 2005).

$\mathrm{Na}$ cultivar MN 721, no período de colheita dos 118 aos 129 dias, houve decréscimo de 3\% na germinação enquanto para a cultivar Scarlett obteve-se o maior percentual de germinação aos 118 dias após a semeadura, o qual, foi diminuindo linearmente à medida que se retardou o processo de colheita. Embora não se tenha verificado grande variação da germinação, a redução da capacidade de germinar é uma 
das conseqüências do avanço do processo de deterioração das sementes, sendo que pequenas diferenças na porcentagem de germinação de um lote podem representar grandes diferenças com relação ao processo de deterioração; esse comportamento diferenciado entre as cultivares, pode ser devido à adaptação das cultivares fazendo com que a associação entre o teor de água das sementes e condições climáticas tenha consequiências diferentes.

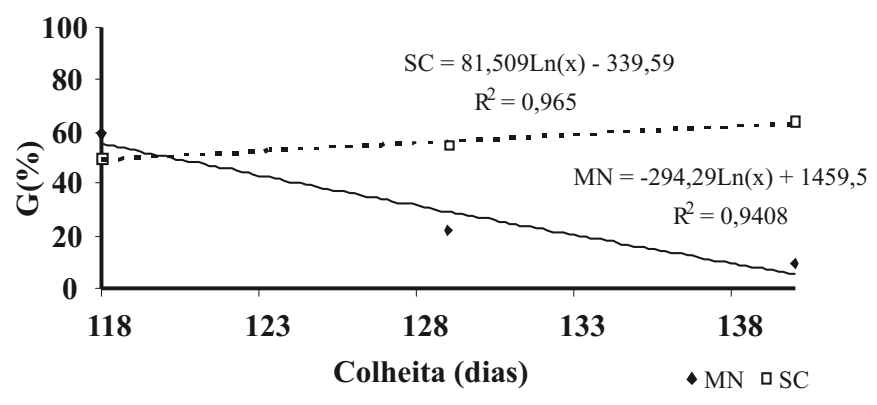

FIGURA 1. Germinação média de sementes de cevada das cultivares MN 721 (MN) e Scarlett (SC), sem superaçãode dormência, ao longo das épocas de colheita $(118,129$ e 140 dias após a semeadura).

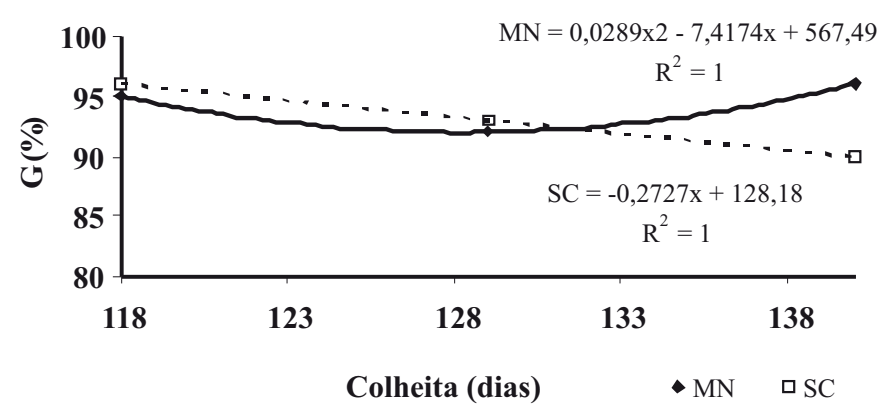

FIGURA 2. Germinação média de sementes de cevada das cultivares MN 721 (MN) e Scarlett (SC), com superação de dormência pelo método de pré-esfriamento, ao longo das épocas de colheita (118; 129 e 140 dias após a semeadura).

O método de pré-esfriamento pode funcionar como instrumento de grande valor para a seleção prévia de lotes de sementes que apresentam bom potencial de emergência em solos frios e úmidos, condições essas que ocorrem, normalmente, na região sul do Brasil (Krzyzanowsky et al., 1999).

A avaliação da qualidade fisiológica das sementes, determinada pelos testes de primeira contagem da germinação, comprimento da parte aérea, comprimento da raiz e fitomassa seca da parte aérea e raiz, encontram-se na Figura 3. As sementes das cultivares MN 721 e Scarlett, depois de superada a dormência, apresentaram rápido estabelecimento das plântulas, como é verificado através da primeira contagem de germinação, onde mais de $90 \%$ das plântulas germinaram até o quarto dia. De acordo com Dias (2001), embora a primeira contagem do teste de germinação seja considerada um indicativo do vigor, sabe-se que durante o processo de deterioração das sementes, a redução da velocidade de germinação não está entre os primeiros eventos. Sendo assim, é um teste que, normalmente, não detecta pequenas diferenças de vigor.

Por outro lado, o crescimento e desenvolvimento de plântulas não apresentaram diferenças significativas para ambas cultivares. Também o sistema radicular tendeu a se desenvolver mais rapidamente que a parte aérea, visto que apresentam, praticamente, o dobro do comprimento. A fitomassa seca acompanhou esses eventos metabólicos e catabólicos de reservas nos tecidos em desenvolvimento e foi correspondente ao comprimento das plântulas.

No teste de envelhecimento acelerado (Figura 4), as sementes mais vigorosas da cultivar MN 721 foram obtidas na segunda colheita e da cultivar Scarlett na primeira e terceira. $\mathrm{O}$ vigor das sementes afeta o desenvolvimento vegetativo e está relacionado ao rendimento, em culturas que são colhidas durante o início do desenvolvimento reprodutivo. Brahma (2008) indicou que não existe a mesma relação para culturas colhidas em plena maturidade reprodutiva, pois o rendimento das sementes, nesse estádio, não está associado ao desenvolvimento vegetativo. $\mathrm{O}$ expressivo resultado que é obtido com o vigor das sementes no período inicial de crescimento, após a emergência, em verdade é no estabelecimento rápido e na ocupação de espaço no solo, pela espécie em cultivo.

O teste de tetrazólio (Figura 4), referente à viabilidade das sementes, foi utilizado para determinar o percentual de sementes vivas, onde se observou a alta qualidade para a produção de sementes. À medida que diminuiu o grau de umidade das sementes, durante a colheita, observou-se uma redução na viabilidade das sementes das cultivares MN 721 e Scarlett. Segundo Bock (1999), a maior parte das mudanças no metabolismo básico das sementes está associada a reduções de viabilidade, as quais afetam diretamente o desenvolvimento das sementes. Com o retardamento da colheita, observou-se que a viabilidade das sementes foi reduzida, provavelmente devido ao consumo 
de reservas nutritivas na fase de pré-colheita, caso em que se deve determinar previamente se o produto desejado é semente ou grão para a produção de malte determinandose, então, o ponto de colheita ideal para cada cultivar e se evitando perdas na produção. Obtiveram-se mais sementes viáveis na primeira colheita (118 dias após a semeadura, maior grau de umidade) para as duas cultivares. Dessa forma, é fundamental determinar o ponto de colheita ideal (grau de umidade) para cada cultivar, para evitar perdas na produção.
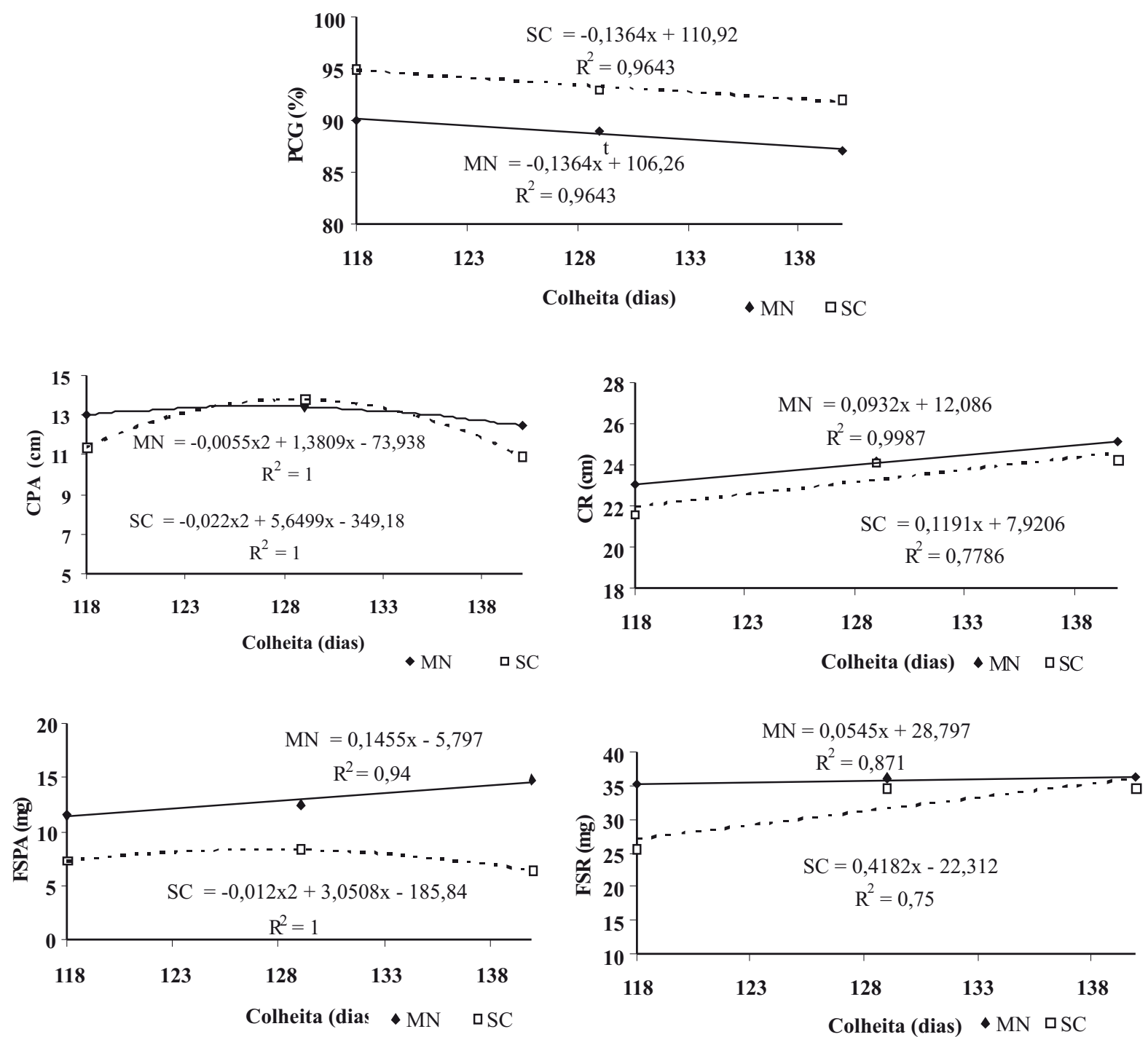

FIGURA 3. Resultados médio de germinação pela primeira contagem (PCG), comprimento da parte aérea (CPA), comprimento do sistema radicular (CR), fitomassa seca da parte aérea (FSPA) e fitomassa seca do sistema radicular (FSR) de sementes de cevada MN 721 (MN) e Scarlett (SC), com superação de dormência pelo método de pré-esfriamento, ao longo das épocas de colheita (118; 129 e 140 dias após a semeadura). 

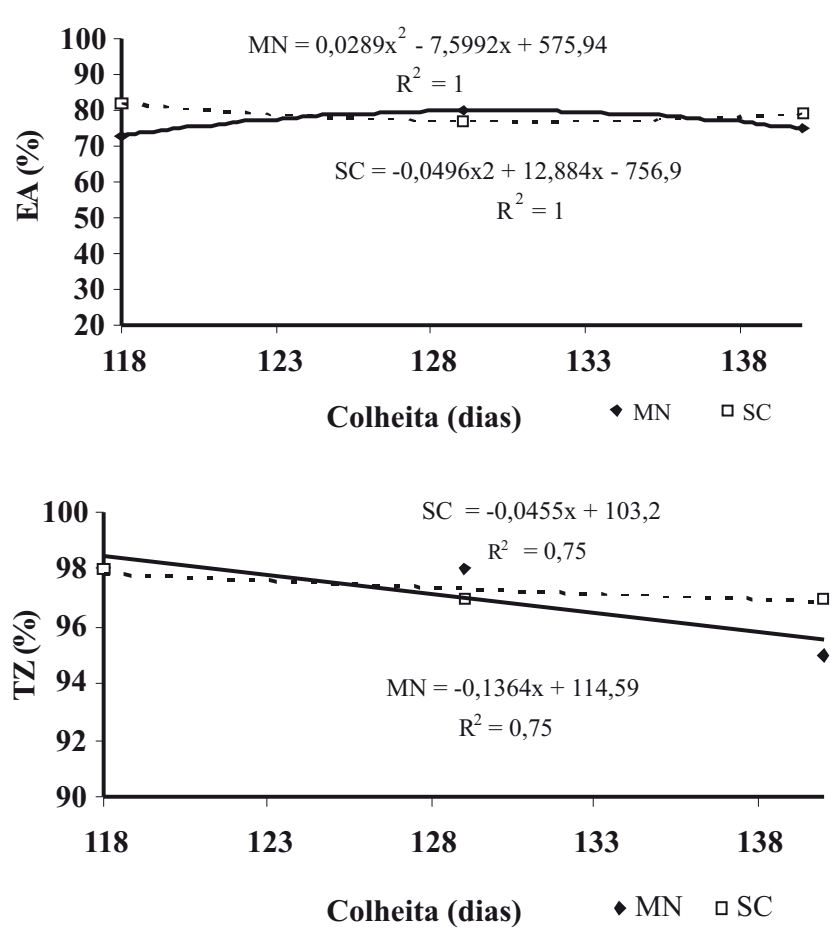

FIGURA 4. Resultados médio de vigor pelos testes de envelhecimento acelerado (EA) e testes de tetrazólio (TZ) e de sementes de cevada, cultivares MN 721 (MN) e Scarlett (SC), com superação de dormência pelo método de pré-esfriamento, ao longo das épocas de colheita (118; 129 e 140 dias após a semeadura).

Os resultados obtidos no trabalho indicaram que, dependendo da época de colheita, existe uma diferenciação no comportamento das sementes. Em função disso, a análise conjunta de vários testes, para analisar a qualidade fisiológica de sementes, tem sido recomendável, pois permitirá verificar modificações que ocorram nas sementes sob a influência do grau de umidade durante o processo de colheita.

\section{CONCLUSÕES}

As cultivares de cevada após a colheita apresentam alta intensidade de dormência.

De acordo com a cultivar, a dormência manifesta-se mais acentuada quando as sementes são colhidas com grau de umidade em torno de $13 \%$.

A antecipação da colheita, com as sementes de cevada contendo grau de umidade entre 18\% (129 dias após a semeadura) e $26 \%$ (118 dias após a semeadura), favorece a qualidade fisiológica.

\section{REFERÊNCIAS}

BARROS, A.C.S.A.; PESKE, S.T. Produção de sementes. In: PESKE, S.T.; LUCCA FILHO, O.; BARROS, A.C.S.A. (Ed.). Sementes: fundamentos científicos e tecnológicos. Pelotas: Universitária/UFPel, 2006, p.470.

BOCK, F.L. Resposta a nível molecular do envelhecimento artificial, natural e pré-condicionamento de sementes e soja. Pelotas. 1999. 27f. Dissertação (Mestrado em Ciência e Tecnologia de Sementes), Universidade Federal de Pelotas, Pelotas.

BRAHMA. Cevada: matéria-prima da cerveja. Net, São Paulo, março 1998. Disponível em: <http://www. brahma. com.br/produtos/cervejas/inst/cervmateria $7 . \mathrm{htm}>$. Acesso em: 10 mar. 2008.

BRASIL. Instrução Normativa ${ }^{\circ} 24$, de 16 de dezembro de 2005. Diário Oficial da União, Brasília, DF, 20 de dezembro de 2005, n 243 , seção I, p.20.

BRASIL. Ministério da Agricultura e Reforma Agrária. Secretaria Nacional de Defesa Agropecuária. Departamento Nacional de Defesa Vegetal. Coordenação de Laboratório Vegetal. Regras para análise de sementes. Brasília, DF, 1992. 365p.

BRASIL.MinistériodaAgricultura,PecuáriaeAbastecimento. Portaria $n^{\circ} 691$ de 22 de novembro de 1996. Diário Oficial da União, 25 novembro, 1996, seção I, p.24751-24752.

DIAS, D.C. Maturação de sementes. Seed News, v.5, n.6, p.3-4, 2001.

FIALA, F. Ensayo al tetrazólio de aleurona. In: PERRY, D.A.; FIALA, F. Manual de métodos de ensayos de vigor. Madrid: Instituto Nacional de Semillas y Plantas de Vivero. Ministério de Agricultura, pesa y alimentacion, 1984. p.4749.

KRZYZANOWSKI， F.C.; VIEIRA， R.D. Deterioração controlada. In: KRZYZANOWSKI, F.C.; VIEIRA, R.D.; FRANÇA NETO, J.B. (Ed.) Vigor de sementes: conceitos e testes. Londrina: ABRATES, 1999. cap.6.1, p.6-8.

MARCOS FILHO, J. Teste de envelhecimento acelerado. In: VIEIRA, R.D.; CARVALHO, N.M. Testes de vigor em sementes. Jaboticabal: FUNEP, 1994. p.133-149.

MARCOS FILHO, J. Fisiologia de sementes de plantas cultivadas. Piracicaba: FEALQ, 2005. 495p.

NAKAGAWA, J. Testes de vigor baseados no desempenho de plântulas. In: KRZYZANOWSKI, F.C.; VIEIRA, R.D.; FRANÇA-NETO, J.B. (Ed.). Vigor de sementes: conceitos e testes. Londrina: ABRATES, 1999. cap.2.1, p.2-21.

NAKAGAWA, J. Testes de vigor baseados na avaliação 
de plântulas. In: VIEIRA, R.D.; CARVALHO, N. M. (Ed.) Testes de vigor em sementes. Jaboticabal: FUNEP, 1994. $164 p$.

PÁDUA, G.P., VIEIRA, R.D. Deterioração de sementes de algodão durante o armazenamento. Revista Brasileira de Sementes, v.23, n.2, p.255-262, 2001.

POPINIGIS, F. Fisiologia da semente. 2.ed. Brasília, DF: AGIPLAN, 1985. 289p.

REUSS, R.; CASSELLS, J.A.; GREEN, J.R. Malting barley: storage, dormancy and processing quality. In: AUSTRALIAN POSTHARVEST TECHNICAL CONFERENCE, 1., 2003, Camberra. Proceedings... Camberra: Stored Grain Research Laboratory, 2003. p. 44-48.

STERLING, M.; BAKER, C.J.; BERRY, P.M.; WADE, A. An experimental investigation of the lodging of wheat.
Agriculture and Forest Meteorology, v.119, p.149-165, 2003.

STORCK, L.; GARCIA, D.C.; LOPES, S.J.; ESTEFANEL, V. Experimentação vegetal. 2.ed. Santa Maria: UFSM, 2006. 198p.

VIEIRA, E.H.N.; RAVA, C.A. Sementes de feijão: produção e tecnologia. (Ed.). Santo Antônio de Goiás: Embrapa Arroz e Feijão, 2000. 270p.

ZIMMER, P.D. Produção de sementes. In: PESKE, S.T.; LUCCA FILHO, O.; BARROS, A.C.S.A. (Ed.). Sementes: fundamentos científicos e tecnológicos. Pelotas: Universitária/ UFPel, 2006, 470p.

YALÇIN, E.; ÇELIK, S.; AKAR, T.; SAYIM, I.; KÖKSEL, $H$. Effects of genotype and environment on b-glucan and dietary fiber contents of hull-less barley grown in Turkey. Food Chemistry, v.101, p.171-176, 2007. 